José Gesto Rodríguez*

\title{
Más allá del COVID-19: \\ algunas consideraciones desde el ordenamiento territorial
}

\section{Cómo citar:}

Gesto, J (2020). Más allá del COVID-19: algunas consideraciones desde el ordenamiento territorial.

Designia, 8(1), 9-15

* Doctor en Gobierno y Administración Pública, ELCPAPO, México. Departamento de Investigación de la Universidad Abierta de Tlaxcala, A.C. E-mail: campus.off@gmail.com ORCID: https://orcid.org/0000-0001-9396-6020
Palabras clave:

Acuaponía, despliegue de la función COVID-19, coronavirus, pandemia, crisis, repercusiones. .

\section{Key words:}

OVID-19, coronavirus, pandemic, crisis, repercussions.

\section{Resumen:}

El COVID-19 ha generado una crisis mundial inimaginable en diversos contextos. En la actualidad, la humanidad se encuentra en una situación de radical incertidumbre, ante las posibles repercusiones de la pandemia. No obstante, sus considerables impactos ya han sido notables en la economía, y las proyecciones en esta área, sugieren una recesión que podría prolongarse. En el ámbito geopolítico, destaca la fragilidad en algunos bloques de poder y el surgimiento de nuevos liderazgos, con tendencia hacia el multilateralismo basado en la cooperación, como nuevo instrumento del orden mundial; en el aspecto social, se advierte sobre los riesgos a la privacidad debido a la vigilancia digital. La sociedad avanza hacia un cambio de estructuras y sistemas establecidos, con un nuevo orden internacional interurbano donde las ciudades cobran protagonismo en un proceso de desglobalización, que demanda transformaciones desde el punto de vista urbano y arquitectónico hacia nuevos formas y estilos de convivencia colectiva. 


\begin{abstract}
:
COVID-19 has generated an unimaginable global crisis in various contexts. At present, humanity is in a situation of radical uncertainty, in the face of the possible repercussions of the pandemic. However, its considerable impacts have already been notable in the economy, and projections in this area suggest a recession that could continue. In the geopolitical sphere, it highlights the fragility in some power blocks and the emergence of new leaderships, with a tendency towards multilateralism based on cooperation, as a new instrument of world order; In the social aspect, it is warned about the risks to privacy due to digital surveillance. Society is advancing towards a change in established structures and systems, with a new interurban international order where cities take center stage in a deglobalization process, which demands transformations from the urban and architectural point of view towards new forms and styles of collective coexistence.
\end{abstract}

En la actualidad, la humanidad afronta una crisis mundial sin precedentes para la generación presente; ninguna pandemia previa a la del COVID-19, o coronavirus (como se denomina de forma genérica y común) (Real Academia Española, 2020), había sido tan siderante y de magnitud equiparable (Fuente; 2020, Harari, 2020; Niño, 2020; Ramonet, 2020). Las decisiones que en lo sucesivo tomen los ciudadanos y los Estados, moldearán los sistemas sanitarios, la economía, la política, la cultura, y otros aspectos que caracterizarán al mundo de una manera inusualmente distinta; como ya es sabido, las emergencias, suelen acelerar los procesos históricos (Niño, 2020; Harari, 2020). A continuación, se pretende hacer un breve esbozo sobre algunos posibles impactos de esta problemática multidimensionalmente compleja, desde la perspectiva de diversos actores. 


\section{MARCO TEÓRICO}

\section{Las repercusiones más evidentes}

Según la Organización de las Naciones Unidas (ONU), "el coronavirus es el mayor reto para el mundo desde la Segunda Guerra Mundial" (Lissardy, 2020, párr. 5). Independientemente de la realidad y de las especulaciones surgidas en torno a origen, así como lo cuestionable de la transparencia de China ante la crisis y de su responsabilidad sobre la propagación mundial del virus (Sands et al., 2020; Diario Las Américas, 2020); lo cierto es que la humanidad se encuentra actualmente sucumbida ante "una situación de incertidumbre radical que no permite anticipar cuál será el impacto de la pandemia" (Niño, 2020; Steinberg, 2020).

Gracias a la primera cuarentena global acaecida en la historia de la civilización humana, la economía mundial está paralizada (Ramonet, 2020). En la totalidad del planeta hay crisis; así como también de la oferta y la demanda. Las estadísticas pronostican que de los ciento noventa (190) países que existen, unos ciento sesenta (160) de ellos, mostrarán un crecimiento negativo en el año 2020; lo que puede considerarse como una tragedia económica que supera los estragos de la Gran Recesión de 1929 (Fondo Monetario Internacional, 2020; Ramonet, 2020).

Específicamente, según afirmaciones de la ONU, las restricciones al movimiento, conjuntamente con las medidas de confinamiento, están suscitando "un efecto muy duro en las economías de Europa y Norteamérica, sobre todo en sectores como el comercio, el ocio, la hostelería y los transportes, que suponen más de un cuarto de los empleos" (Guterres, 2020, párr. 9). "El colapso de la economía mundial ya deja millones de desempleados" (Lissardy, 2020, párr. 34); se han hundido las bolsas de valores con altibajos y los mercados financieros del mundo, sufren fuertes descensos (Gutiérrez, 2020); los precios del petróleo han caído en los más desconocidos abismos (Barría, 2020; Pardo, 2020).

Se presume además, que "el confinamiento y el cierre de la actividad económica puede agravar la situación de pobreza en la que viven millones de personas, generando situaciones de inestabilidad que pueden originar una crisis peor a la sanitaria" (Instituto Español de Estudios Estratégicos, 2020, p. 4). Particularmente, Blanco (2020) afirma que también América Latina afrontará próximamente una crisis profunda, "que será generalizada en todos los países y afectará a todos los sectores económicos". En general, "el tejido empresarial experimentará un fuerte impacto negativo, y sus ciudadanos verán perjudicada su renta y bienestar de forma notable” (párr. 23) 
Por otra parte, se vaticina un cambio de extrema significancia en el ámbito geopolítico. En este sentido, Lissardy (2020) señala que "si la recesión se extiende, podría causar mayor inestabilidad global, más fisuras en Europa y escalar los roces ya visibles entre Occidente y China, la gran potencia emergente" (párr. 34). Es evidente la notable fragilidad en algunos bloques de poder, así como en otros, el escaso interés por el liderazgo (Zapata, 2020); "el orden global ha dejado de ser norteamericano para hacerse más multilateral" (Fuente, 2020, p. 3). En efecto, los desafíos a los que se enfrenta la humanidad exigen, ahora más que nunca, "respuestas multilaterales basadas en una cooperación entre Estados que China no está en condiciones de liderar". (Fuente, 2020, p. 3).

Finalmente, en lo que se refiere al impacto socio-cultural, destaca el hecho de que esta pandemia, es la primera enfermedad de carácter global contra la que se lucha en forma digital. No obstante, esto sugiere consecuentes implicaciones y riesgos para la privacidad individual; así como la inminente posibilidad de surgimiento de una vigilancia masiva digital por parte de los Estados, que pudiera servir como medio de control social. Se advierte que las medidas, supuestamente excepcionales, adoptadas por los poderes públicos para contener la pandemia, podrían asegurar su permanencia en el futuro, sobre todo, aquellas referidas a la cibervigilancia y el biocontrol (Ramonet, 2020).

\section{Hacia un nuevo orden mundial}

El hecho de que las potencias, consideradas como las más poderosas del mundo y con las tecnologías más sofisticadas, han sido incapaces de frenar la expansión planetaria del virus COVID-19, ubica a la humanidad ante una impactante realidad. Las sociedades, después de la pandemia, exigirán la materialización de cambios profundos en los mecanismos que accionan y regulan la respuesta de los Estados, pese a que ello sugiera el cuestionamiento del sistema internacional como hasta ahora ha sido entendido (Fuente, 2020; Ramonet, 2020; Zapata, 2020).

La irrupción de esta enfermedad, somete al orden establecido, así como a las estructuras de gobernanza y a los sistemas previos creados, a nuevas y poderosas tensiones. En esta nueva situación y realidad, las ciudades cobran protagonismo de forma sistemática, cuestionando precisamente, ese orden hacia las estructuras y sistemas instituidos (Sánchez, 2020). Tras el debilitamiento de este flagelo a la salud colectiva, se espera que sus efectos materiales y morales induzcan a cambios en la organización social y en la actitud humana ante distintos aspectos de la cotidianidad; así mismo, que las ciudades recobren su dinamismo y vitalidad (Instituto Español de Estudios Estratégicos, 2020). “Ante la nueva realidad global, se sostiene -incluso 
antes de la pandemia actual - que el nuevo orden internacional será interurbano" (Varinsky, 2016, citada por Sánchez, 2020, p. 17). De hecho, existe una marcada tendencia hacia la desglobalización, "un proceso en el que la economía, pero también la sociedad, la política y la cultura, tras una etapa de interacción e interdependencia mundial, se vuelven más regionales que nunca" (Llopart, 2020).

Atendiendo a esta premisa, resulta indudable también que la pandemia plantea el desafío urbanístico, no solo de repensar la importancia y el rol de las ciudades, sino también de su arquitectura, bajo parámetros de sostenibilidad. Concretamente, la prevención o inhibición a futuras pandemias, sugiere la necesidad de dilucidar otros modelos de densidad física y arquitectura urbana que permitan la comunicación de las personas, el socializar con sus vecinos y participar en la vida colectiva, aunque temporalmente estén separadas (Sennet, 2020).

\section{CONCLUSIONES}

Ante la crisis que enfrenta el mundo gracias al COVID-19, la humanidad se encuentra en una situación de incertidumbre, debido a lo impredecible de los impactos de la pandemia. Algunos efectos son evidentemente notables: la paralización de la economía, la crisis de la oferta y la demanda, la disminución el crecimiento económico de casi todos los países, el desempleo, la caída de las bolsas de valores y de los mercados financieros, la baja en los precios del petróleo; sin olvidar, las posibles repercusiones en los niveles de pobreza de los sectores más vulnerables. Destacan además, los posibles cambios en el contexto geopolítico, donde el multilateralismo fundamentado en la cooperación entre Estados, emerge como una de alternativas más viables en el nuevo orden mundial. En el ámbito socio-cultural, se advierte sobre los riesgos y consecuencias de la vigilancia digital que han adoptado algunos gobiernos, como medida ante la emergencia. Por último, se espera que los efectos materiales y morales susciten un cambio en la organización social donde las ciudades son elementos importantes de un proceso desglobalización; los cambios en el urbanismo y en la arquitectura, incluso, forman parte estas transformaciones. 


\section{REFERENCIAS BIBLIOGRÁFICAS}

Barría, C. (20 de abril, 2020). “Caída del precio del petróleo: las consecuencias para América Latina de la caída del valor del crudo en medio de la crisis por el coronavirus". BBC News Mundo. Recuperado el 12 de mayo de 2020 de: https://www.bbc.com/mundo/noticias-51807458

Blanco, A. (2020). "El profundo, pero transitorio, impacto del COVID-19 en la economía latinoamericana". Fundación Real Instituto Elcano. Recuperado el 12 de mayo de 2020 de: http://www.realinstitutoelcano. org/wps/portal/rielcano_es/contenido?WCM_GLOBAL_CONTEXT=/elcano/elcano_es/zonas_es/ ari63-2020-blanco-profundo-pero-transitorio-impacto-covid-19-en-economia-latinoamericana

Diario Las Américas (17 de abril, 2020). “¿China dice toda la verdad sobre el coronavirus?”. Recuperado el 12 de mayo de 2020 de: https://www.diariolasamericas.com/mundo/china-dice-toda-la-verdad-el-coronavirus-n4197276

Fondo Monetario Internacional [FMI] (15 de abril, 2020). "El FMI avisa de tres escenarios en los que la crisis será aún mucho peor". El País Economía, Cinco Días. Recuperado el 12 de mayo de 2020 de: https:// cincodias.elpais.com/cincodias/2020/04/14/economia/1586898756_376524.html

Fuente, I. (2020). "El mundo después de la pandemia: el nuevo orden no será chino". Documento de Opinión IEEE 33/2020. Recuperado el 12 de mayo de 2020 de: http://www.ieee.es/Galerias/fichero/docs_opinion/2020/ DIEEEO33_2020IGNFUE_mundo.

Guterres, A. (16 de abril, 2020). "La ONU alerta sobre contracción de la economía mundial por pandemia”. El Tiempo. Recuperado el 12 de mayo de 2020 de: https://www.eltiempo.com/mundo/mas-regiones/ cuales-son-las-consecuencias-de-la-pandemia-sobre-la-economia-mundial-segun-la-onu-479980

Gutiérrez, H. (12 de marzo, 2020). “El pánico hunde unas Bolsas en caída libre: el Ibex se desploma un 14,06\%, el mayor batacazo de su historia". El País. Recuperado el 12 de mayo de 2020 de: https://elpais.com/ economia/2020-03-12/las-bolsas-sufren-en-la-apertura-y-el-ibex-cae-mas-de-un-5.html

Harari, Y. (20 de marzo, 2020). "Yuval Noah Harari: the world after coronavirus". Financial Times. Recuperado el 12 de mayo de 2020 de: https://www.ft.com/content/19d90308-6858-11ea-a3c9-1fe6fedcca75

Instituto Español de Estudios Estratégicos [IEEE] (15 de abril, 2020). “IEEE. ...y en esto llegó el virus”. Documento Informativo IEEE 14/202. Recuperado el 12 de mayo de 2020 de: http://www.ieee.es/Galerias/fichero/ docs_informativos/2020/DIEEEI14_2020IEEE_COVID19.pdf

Lissardy, G. (5 de mayo, 2020). “Coronavirus: los 2 grandes escenarios mundiales que plantean algunos expertos para después de la pandemia". BBC News Mundo. Recuperado el 12 de mayo de 2020 de: https://www.bbc.com/mundo/noticias-internacional-52526090 
Llopart, E. (23 de abril, 2020). “Cómo el coronavirus está acelerando el proceso de desglobalización". La Vanguardia. Recuperado el 12 de mayo de 2020 de: https://www.lavanguardia.com/ economia/20200423/48678195571/coronavirus-acelerando-proceso-desglobalizacion-brl.html

Niño, S. (19 de marzo, 2020). "El mundo, tras el virus, será otro". Diario Hoy de Extremadura. Recuperado el 13 de mayo de 2020 de: ttps://www.hoy.es/economia/santiago-nino-becerra-coronavirus20200319195712-ntrc.html

Ramonet, I. (25 de abril, 2020). "La pandemia y el sistema-mundo". La Jornada. Recuperado el 12 de mayo de 2020 de: https://www.jornada.com.mx/ultimas/mundo/2020/04/25/ante-lo-desconocidola-pandemia-y-el-sistema-mundo-7878.html\#.XqdvsiHw9kU.whatsapp

Pardo, J. (2020). “Coronavirus y petróleo: consecuencias geopolíticas”. Documento de Análisis IEEE 15/2020. Recuperado el 15 de mayo de 2020 de: http://www.ieee.es/contenido/noticias/2020/05/DIEEEA15_2020JOSPAR_petroleo.html

Real Academia Española (2020). “Crisis del COVID-19: sobre la escritura de coronavirus”. Recuperado el 12 de mayo de 2020 de: https://www.rae.es/noticias/crisis-del-covid-19-sobre-la-escritura-de-coronavirus

Sánchez, P. (2020). “Pandemias y ciudades: ¿Hacia un orden mundial urbacéntrico?”. Documento de Análisis IEEE 14/2020. Recuperado el 12 de mayo de 2020 de: http://www.ieee.es/Galerias/fichero/ docs_analisis/2020/DIEEEA14_2020PEDSAN_urbacentrico.pdf y/o enlace bie3

Sands, G.; Atwood. K.; Collison, S. \& Bohn. K. (04 de mayo, 2020). “China ocultó intencionalmente la gravedad del coronavirus, sostiene informe del gobierno de EE.UU". CNN. Recuperado el 12 de mayo de 2020 de: https://cnnespanol.cnn.com/2020/05/04/informe-del-gobierno-de-ee-uu-consideraque-china-oculto-intencionalmente-la-gravedad-del-coronavirus/

Steinberg, F. (2020). “Coronavirus: amenaza económica, respuesta política e implicaciones”. Fundación Real Instituto Elcano. Recuperado el 12 de mayo de 2020 de: http://www.realinstitutoelcano.org/ wps/portal/rielcano_es/contenido?WCM_GLOBAL_CONTEXT=/elcano/elcano_es/zonas_es/ ari22-2020-steinberg-coronavirus-amenaza-economica-respuesta-politica-e-implicaciones

Varinsky, D. (19 de agosto, 2016). "Cities are becoming more powerful than countries", Business Insider. Recuperado el 12 de mayo de 2020 de: https://www.businessinsider.com/ why-cities-are-more-powerful-than-countries-2016-8?IR=T

Zapata, J. (14 de abril, 2020). “El coronavirus ya está produciendo cambios en el orden mundial y la geopolítica del poder". Alnavío. Recuperado el 12 de mayo de 2020 de: https://alnavio.com/ noticia/20780/actualidad/el-coronavirus-ya-est-produciendo-cambios-en-el-orden-mundial-y-lageopoltica-del-poder.html 